\title{
The assessment of bidding strategy of Iranian construction firm
}

\author{
M. T. Banki*, B. Esmaeeli, M. Ravanshadnia \\ Department of Civil \& Environment Engineering, Amir kabir University of Technology, Tehran, Iran
}

(Received December 12 2007, Revised June 9 2008, Accepted December 2 2008)

\begin{abstract}
Arriving at the final bid price is a critical decision which is mostly done through experience and intuitions. As, many factors affect the final proposed price, no quantified decision processes may lead to irrational low or high proposed prices. Therefore, various attempts have been done to propose systematic models to track and analyze the bidding trends. This paper focuses on the previous trends of the bidding prices to estimate proper bidding cost in the Iranian construction industry The prices might be influenced by external characteristics such as competitors' policies, the number of tendered projects, the number of contractors competing in the current tender, project characteristics, and the client. The subject of bidding price can be investigated through the client view or the contractor view. This paper attends the second approach. This paper present a quantitative analysis of impact of number of bidders on project bid prices. The study found that increasing the number of bidders will result in decreased project bid prices.
\end{abstract}

Keywords: bidding strategy, statistical analysis and number of bidders

\section{Introduction}

Estimating and bidding are two important functions performed by construction contractors. Many of the decisions required in arriving at the final bid price are based on experience and intuition. Deciding on an appropriate margin, or markup, to add to the estimated cost of a project is one such decision ${ }^{[3]}$.

The only possible way for a contractor firm to survive and acquire its aims are winning tenders and making profit. Although in some cases, the contractors undertake projects and make profit without having to win a tender, this is not the usual application. Contract bidding, like all other forms of pricing, is essentially about contractors making strategic decisions in respect of which contracts to bid and the bid levels necessary to secure them ${ }^{[2]}$.

The subject of the bidding strategy has interested various researchers in America and Europe since the mid-1950s ${ }^{[10]}$. Numerous researchers have developed models for bid/no bid and mark-up size decisions. However, it is difficult to develop realistic models that capture the complexity and uncertainty of the full construction contract bidding situation, which is perhaps why many contractors did not show interest in such models ${ }^{[2]}$. The complexity of the problem, regarding the two decisions in bidding stage, is so overwhelming that even the experienced contractors feel that the industry should have a better technique for arriving at bid/no bid or mark-up size decisions.

The authors rightfully stated that there is a renewed interest in the competitive bidding problem and indicated that over the last five decades there has been a relatively modest addition to the state of the art. Osama Moselhi, and Tarek Hegazy ${ }^{[11]}$ suggested that bidding strategy models be grouped into three main categories (see Fig. 1): (1) Models based on probability theory [e.g., Friedman (1956) ${ }^{[6]}$ and Gates (1967) ${ }^{[7]}$ ] to maximize the expected profit; (2) models based on decision-support systems [e.g., Ahmad and Minkarah $\left.(1987)^{[1]}\right]$ to account for the multi attributed nature of bidding decisions; and (3) newly emerging models

\footnotetext{
*Corresponding author. E-mail address: mtbanki@yahoo.com; esmaeeli_behzad@yahoo.com.
} 


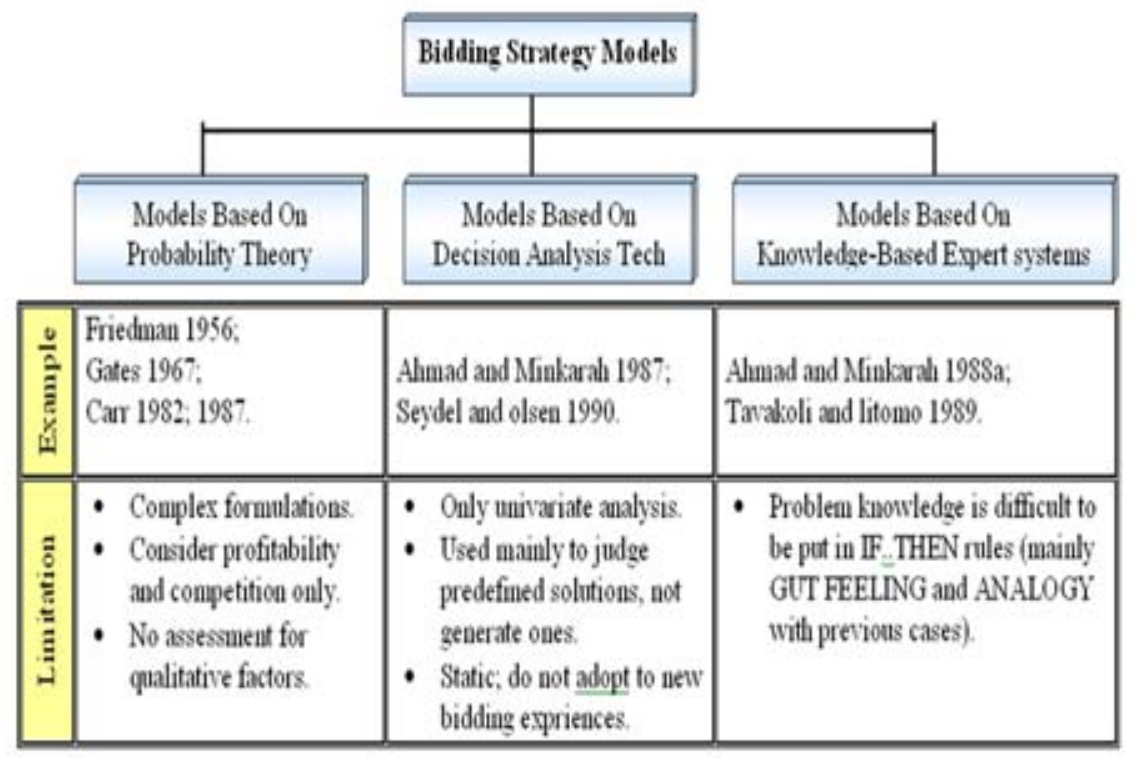

Fig. 1. Bidding strategy models

based on artificial intelligence techniques [e.g., Tavakoli arid Utomo $(1989)^{[13]}$ ] to consider the heuristic and unstructured nature of such a decision problem.

There is a great volume of literature concerned with bidding strategies. The basic assumption of all the bidding calculations is that a relationship exists between the tender sum and the 'probability' or 'chance' of winning the contract ${ }^{[10]}$. The aim of probabilistic models is to express this numerically. In entering a bidding competition it is assumed that the contractors first estimate their costs and then add a mark-up to cover profit (or a mark-up to cover contribution, i.e. profit and company overheads).

The aim of most of these workers has been the development of a 'probabilistic model' which will predict the chances of winning in the type of competitive bidding that is common in the construction industry. These probabilistic models have attempted to give guidance to bidders by producing statements of the type: 'If you bid at mark-up of $12 \%$ you have $30 \%$ chance of winning this contract ${ }^{[10]}$. Following on from these calculations of probability previous workers have attempted to drive a mark-up which purports to represent the 'optimum mark-up', that is the mark-up which in the long term will produce the maximum profit. The optimum mark-up theories so far devised have not taken into account the varying success a company might experience in fining its available capacity or budgeted turnover. Therefore, recent work has suggested the use of probability calculations as a means for predicting the overall success ratio (number of jobs won/number of bids submitted) to control work acquired. This is achieved by raising mark-ups when the order book is full and work is plentiful and reducing the mark-up when the market and order book are depressed ${ }^{[10]}$.

This paper provides several significant contributions. The paper develops a regression model to quantify the impacts of greater or less competition within a robust bidding exercise. The regression analysis also identifies the nature of varying bid activity dynamics, as the loss or addition of bidders.

\section{Literature survey}

Researchers have been concerned with the problem of bidding strategy since the mid-1950s. Since Friedman's ${ }^{[6]}$ mathematical model, which is known to be the first one, the literature has been flooded with many bidding models. However, most of these models remained in academic circles and did not find their way into the practical world ${ }^{[10]}$.

Fayek $^{[3]}$ presents a competitive bidding strategy model for use in setting a mark-up for construction projects. Fayek et al. studied bidding practices in Australian and Canadian construction industries ${ }^{[4,5]}$. Jaselskis and Talukhaba ${ }^{[8]}$ focus on bidding considerations in developing countries, considering the inherent risks 
existing specifically in these countries regarding this issue. Wanous et al. ${ }^{[14]}$ had a questionnaire survey among Syrian contractors. Li et al. ${ }^{[9]}$ applies artificial neural networks for construction mark-up estimation.

Each of these studies had valuable contributions to bidding and mark-up decisions separately.

Whittaker $\left(1970^{[15]}, 1981^{[16]}\right)$ analyzed a number of contracts relating to building projects and produced an 'overall distribution' of bids which was uniform in shape. Given that you could estimate the mean bid accurately (to within 2\%). The Whittaker distribution or model will tell you the probability of any particular bid being the winning bid. Whittaker reports that in tests he has shown a significant improvement when compared to bidding unsupported by his model.

McCaffer (1976) ${ }^{[10]}$, sympathizing with the approach of Whittaker, undertook a similar analysis. He produced distributions of bids for roads and building works which were shown to be virtually normal distributions with standard deviations of $8.4 \%$ for road contracts and $6.3 \%$ for buildings contracts. The use of these overall distributions, or the distributions for contracts grouped together by the number of bidders, makes it possible to predict the lowest bid from an estimate of the mean bid. It must be emphasized that such figures would need to be compiled for each type of contract in each area, and that the figures shown are not necessarily universally applicable.

Few research studies have been conducted to evaluate the relationship between the number of bidders on a project and the bid price for the work. This research has been undertaken to attempt to replicate the findings and positions of earlier, published and unpublished investigations, within a controlled group of projects where the number of bidders, can be analyzed discretely.

\section{Nature of bidding in construction}

Competitive bidding is widely applied in many sectors besides construction The different forms of bidding reflect one of two types; open bidding or sealed bidding, or a combination of these two extremes ${ }^{[10]}$. Open bidding employs an iterative negotiation process, whereby each contractor independently negotiates a contract price with the client. Consultation among competing contractors is allowed, and contractors are allowed to revise their bid for as long as the client has not come to a decision on which bid to accept. The open form of bidding is widely used in the commercial sector. Sealed bids on the other hand, are more typical of the construction and civil engineering sector. In sealed bids, each contractor is allowed to submit only one bid, and negotiation between the client and competing contractors is barred. Equally, discussion pertaining to the project under bid between the competing contractors is not allowed. Each contractor's bid is submitted by a specified date, and once submitted (usually in a sealed envelope) cannot be revised.

In Fig. 1 the process of strategic decision making in bidding is shown. The process incorporates tree broad groups of factors: Internal, external and enviromental factors. Internal factors are those related to the company such as the expertise, experience, resources, capabilties, etc. Externals factors, outside the company, include the number of bidders, bidding risk, type of project, cashflow requirements, bid related factors and etc. enviromental factors, social and economic condition, include availability of other projects, availability of qualified labor, availability of qualified stafs, availability of qualified subcontractor, availability of equipment. These three factors interactively affect the strategic decisions of competetive bidding in construction industry. This research has focused on one of the external factors, number of bidders, as a matter of interest. Regression analysis used to find any correlation between number of bidders and bid price.

\section{Research environment}

In Iran, planning and management organization has responsibility to give grads to all of the contractors in all types of construction. It is governmental organization and every year publishes lists of contractors and consultants which has got grades. The firm that is more capable will get first degree and a firm with degree of five is less capable. The scope of this study is limited to the first grade domestic construction firms which are classified as first grade by the Management an Programming Organization (M.P.Org.).

Usually, these contractors have estimation units, which evaluate the project items and analyzes it with the domestic national unit price announced by MP.Org and propose appropriate mark up. Then the final decision 
will be made by the managers of the firm. As a rule of thumb, the managers attend the situation of their firm in the previous tenders and modify current mark up rate considering the company bidding strategies.

In cases that have considered in this paper the owners had decided to prequalify all bidders. This had announced in the instruction to bidders. Each contractor interested in preparing and submitting a bid was asked o submit documents that implies its' capability in accomplishing similar types of project. If the owner had doubts regarding the contractor's ability to successfully complete the work, the owner could simply withhold qualification.

In all of the bids, owners require contractors to prepare a bid bond. Bid bond for all contract is 5\% of bid's cost. If a contractor does not prepare bid bond, contractor will be omitted. Among qualified contractors who has proposed lowest bid, would win the contract.

The Iranian construction industry, Now, is experiencing a period of high inflation and a more than ever competing environment. Therefore, the construction firms need systematic mechanisms to apply appropriate bidding strategy.

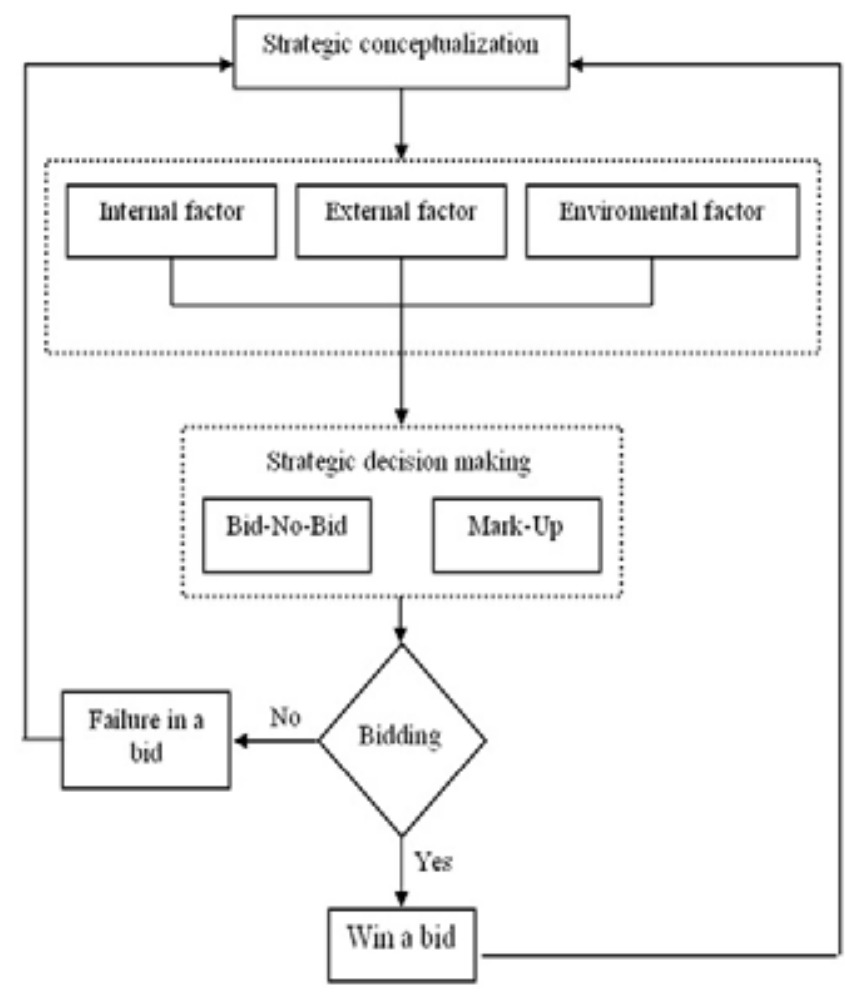

Fig. 2. Process of strategic decision making in bidding

\section{Hypotheses}

There are many definitions of hypothesis testing, however, they can generally be captured in that they are procedures for making rational decisions about the reality of events. Specifically, does one believe there is an effect from one variable upon another? In this case, does the number of bidders participating in a bid competition result in lower bid prices experienced by the project winner? The research belief is that there is likely a relationship between these two factors, and it is statistically explored through the development of a hypothesis, which is then tested.

In this study the hypothesis holds that with a reduced number of bidders there will be an associated increase in project price. Regardless of whether the reduction is due to material limitations, bid timing, overall contractor disinterest, the fewer bid offers received will, on average, result in a higher cost of award to the low, responsible, responsive bidder. 


\subsection{Null hypothesis}

The null hypothesis (H0) of the research is: In the first grade firms Sector of Construction Industry, in Iran; based upon a measure of competition through the number of project bids received, there will be no measurable correlation between number of bidders and deviation measured by the relative difference between the owners' prebid project estimate and the low responsible, responsive bid price offered.

\subsection{Method of analysis}

The research methodology for this study was developed into a multistep series. The first step was to perform a literature review to determine if sufficient evidence existed supporting the theory that increased competition, as measured by the number of bids received, would result in more competitive bids and lower costs.

The second portion of the study investigated the correlation between the increased number of bids and the lowering of the low bid prices. The study included 116 bids, totaling almost $\$ 134$ million in awarded contracts. These bids resulted in the award of 16 prime contracts.

\subsection{Data collection}

Considering the exploratory nature of the research, data collection has been made with the aim of maximizing the number of respondents in order to attain a representative sample of the contractors available in the specific part of market.

The data for the study were collected through retrieval and analysis of the bid results for 16 public works in Iran. The data collected from the 16 separate building programs focused on the value of the awarded contract (bid) prices, each project's budget, and the number of bidders for each project. One hundered sixteen (116) bids received. The data from these projects formed the basis of the data analyzed.

The numbers of bidders were less than 8 in all bids but 3 of them. Total bid price in all of the contracts were more than 5 million dollars (US). Types of the contracts were design-bid-build and were going to bid in 2006.

At the bid opening, a representative of the owner reads and records the bid offer from each contractor submitting a proposal. This record is available for public inspection. Based upon these bid offers, the architect and/or the construction manager will review the bids relative to the projects' budgets and the bidders' qualifications. Based upon the findings of this review, the owner will generally follow one of two paths: (1) accept the bids and award contracts, at which time the project proceeds to construction, or (2) reject the bid proposals, and either rebid the work or abandon the project.

Table 1. Descriptive statistics of overall sample contracts

\begin{tabular}{c|c|c|c|c|c|c}
\hline & Range & Minimum & Maximum & Mean & Standard deviation & $\mathrm{N}$ \\
\hline Number of bidders & 14 & 4 & 18 & 7.25 & 3.531 & 16 \\
\hline Deviation from estimate & 32.70 & -18.31 & 14.4 & -0.912 & 7.938 & 16 \\
\hline
\end{tabular}

\section{Results}

\subsection{Study findings}

Within the data set of 16 projects, the number of bidders, the low (awarded) bid, and the owner's prebid estimate were available. The low bid deviation from the prebid estimate, for the 16 awarded contracts, is presented in Tab. 1.

The data from the 16 awarded projects was then evaluated. A correlation analysis of these data was performed. The results of this analysis are presented in Tab. 2, and indicate that there is indeed a statistically 
Table 2. Pearson correlation - Number of bidders versus deviation from estimate

\begin{tabular}{l|c|c|c}
\hline & & & Deviation From estimate \\
\hline \multirow{3}{*}{ Number of bidders } & Pearson correlation & 1 & $-0.667^{a}$ \\
\cline { 2 - 4 } & Sig. (2-tailed) & & 0.005 \\
\cline { 2 - 4 } & $\mathrm{N}$ & 16 & 16 \\
\hline \multirow{3}{*}{ Deviation From estimate } & Pearson correlation & $-0.667^{a}$ & 1 \\
\cline { 2 - 4 } & Sig. (2-tailed) & 0.005 & - \\
\cline { 2 - 4 } & $\mathrm{N}$ & 16 & 16 \\
\hline
\end{tabular}

Deviation from Pre-Bid estimate VS. Number of bidders

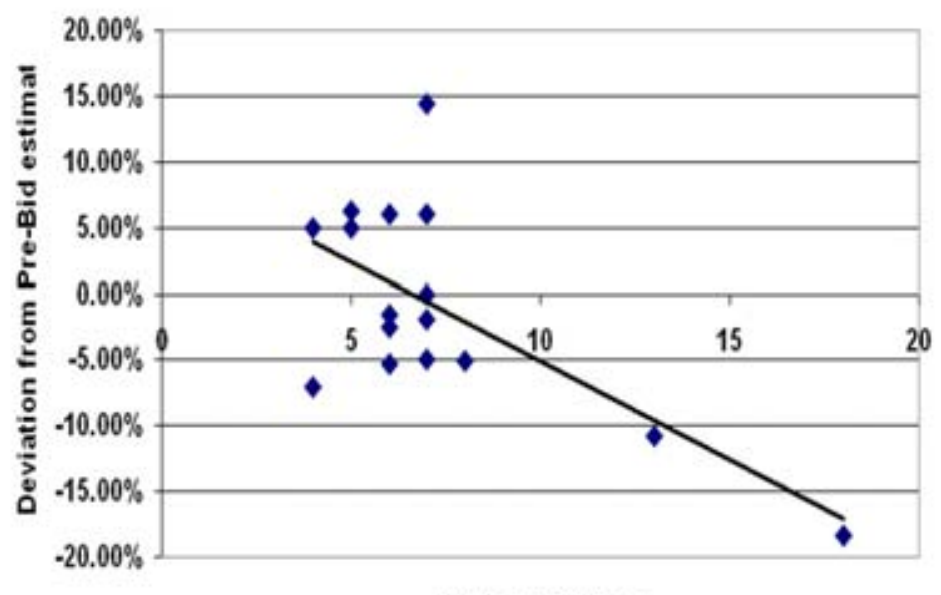

Number of bidders

Fig. 3. Regression plot of number of bidders and deviation from estimate

Table 3. Analysis of variance - low bid deviation versus number of bidders

\begin{tabular}{c|c|c|c|c|c|c}
\hline $\begin{array}{l}\text { ANOVA }^{b} \\
\text { model }\end{array}$ & & $\begin{array}{l}\text { Sum of } \\
\text { squares }\end{array}$ & df & $\begin{array}{l}\text { Mean } \\
\text { square }\end{array}$ & F & significance \\
\hline 1 & Regression & 83.248 & 1 & 83.248 & 11.133 & $0.005^{a}$ \\
\hline & Residual & 103.752 & 14 & 7.411 & - & - \\
\hline & Total & 187.000 & 15 & - & - & - \\
\hline
\end{tabular}

${ }^{a}$ Predictors: (constant), Number of bidders.

${ }^{b}$ Dependent variable: Deviation from estimate.

Table 4. Regression coefficients - low bid deviation versus number of bidders

\begin{tabular}{|c|c|c|c|c|c|c|}
\hline \multirow[t]{2}{*}{$\begin{array}{l}\text { Coefficients } \\
\text { model }\end{array}$} & & \multicolumn{2}{|c|}{$\begin{array}{l}\text { Unstandardized } \\
\text { coefficients }\end{array}$} & \multirow[t]{2}{*}{$\begin{array}{l}\text { Standardized } \\
\text { Coefficients } \\
\text { Beta }\end{array}$} & \multirow[t]{2}{*}{$\mathrm{t}$} & \multirow[t]{2}{*}{ Sig. } \\
\hline & & $\mathrm{B}$ & Standard error & & & \\
\hline 1 & (constant) & 6.978 & 0.685 & - & 10.182 & 0.000 \\
\hline & Number of bidders & -0.297 & 0.089 & -0.667 & -3.352 & 0.005 \\
\hline
\end{tabular}

significant relationship between the number of bidders on a project and the low bid received, relative to the project budget.

The regression model tells us that, on average, for each bidder lost from the competition there will be a $29.7 \%$ increase in project cost. The result is that for the study's main hypothesis, the null is rejected. As the number of bidders is increased, there is a concomitant reduction in the bid price offer from the low bid contractor. 
Then a correlation analysis of the number of bids and the average deviation from the prebid estimate was performed. It was found that there is no statistically significant correlation between the number of bids and the average deviation from the prebid estimate. An ANOVA was performed on this data and there was no significant relation found (sig. $=0.525$ ). The regression data are presented below in Tab. 5 . There is no statistically significant relationship between the number of bidders and an associated reduction in the average bid price. This is visually represented in Fig. 4, the scatter-plot of each bid's deviation from the estimate versus the number of bidders. Although there is a downward slope in the regression line, the data do not support a statistically significant finding.

Table 5. Analysis of variance - Average bid deviation versus number of bidders

\begin{tabular}{|c|c|c|c|c|c|c|}
\hline $\begin{array}{l}\text { ANOVA }^{b} \\
\text { model }\end{array}$ & & $\begin{array}{l}\text { Sum of } \\
\text { squares }\end{array}$ & df & $\begin{array}{l}\text { Mean } \\
\text { square }\end{array}$ & $\mathrm{F}$ & significance \\
\hline \multirow[t]{3}{*}{1} & Regression & 0.001 & 1 & 0.001 & 0.446 & $0.525^{a}$ \\
\hline & Residual & 0.014 & 116 & 0.003 & - & - \\
\hline & Total & 0.015 & 117 & - & - & - \\
\hline
\end{tabular}

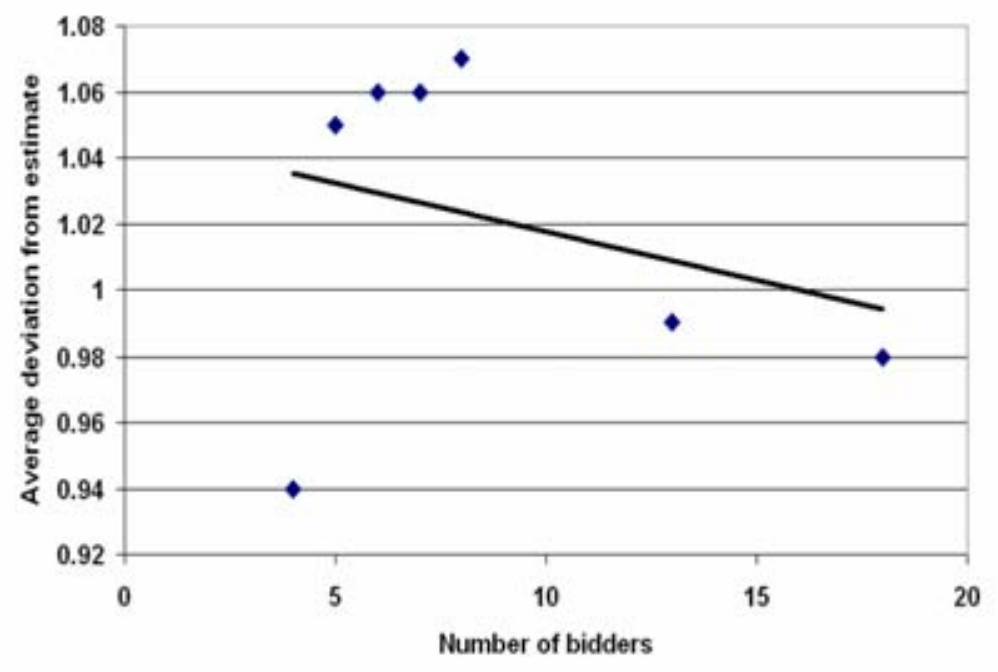

Fig. 4. Regression plot of number of bidders and average deviation from estimate

\section{Conclusion}

The study found that increasing the number of bidders will result in decreased project bid prices. The current research studied the deviation between the low bid and the prebid estimate, compared to the number of bidders, since in the earlier studies, these were the metrics that were evaluated. The established relationship of this work is between the low bid offer, and the number of bidders. The current research has established that the number of bidders impact, in a statistically significant way, the low bid price for the projects.

Overall, the findings of this research work suggest a number of areas for future study. First, a more detailed research study investigating facilities may be appropriate. While the results of this study reflect, in general, the findings of earlier work, there is a limitation in that it addresses specifically contracts with more than 5 million dollars. The evaluation of the final project cost compared to the bid day offer was beyond the scope of this study. Other researches can be conducted to evaluate more data from each type of contract in 
each area of construction market of Iran. The data must categorize in to different type of construction work such as buildings, schools, airport and etc.

The present research relied upon the prebid estimates prepared by the architect's office and their estimating consultant. The accuracy of prebid estimates is always a matter of question. The accuracy should be viewed in light of how well the estimate compares to the low bid offered on bid day (of course with appropriate allowances for construction contingencies). The accuracy of an estimate generally is impacted by three major elements: who prepared the estimate, how it was prepared, and the level of information known at the time of the estimate (Oberlender and Trost 2001).

\section{References}

[1] I. Ahmad, I. Minkarah. An additive utility model for selecting optimum bid price. in: Proc., 18th Annual Pittsburg Conf. on Modelling and Simulation, vol. 18, 1987, 367-373. 18(1).

[2] D. Drew, M. Skitmore. The effect of contract type and size on competitiveness in bidding. Construction Management and Economics, 1997, 15: 469-89.

[3] A. Fayek. Competitive bidding strategy model and software system for bid preparation. Journal of Construction Engineering and Management, 1998, 124(1): 1-10.

[4] A. Fayek, I. Ghoshal, S. AbouRizk. A survey of the bidding practices of canadian civil engineering construction contractors. Canadian Journal of Civil Engineering, 1999, 26: 13-25.

[5] A. Fayek, D. Young, C. Duffield. A survey of tendering practices in the australian construction industry. Engineering Management Journal, 1998, 10(4): 29-34.

[6] L. Friedman. A competitive bidding strategy. Oper. Res., 1956, 4: 104-112.

[7] M. Gates. Bidding strategies and probabilities. Journal of the Construction Division, 1967, 93: 74-107. ASCE.

[8] E. Jaselsis, Talukhaba. A. bidding consideration in developing countries. Journal of Construction Engineering and Management, 1998, 124(3): 185-93.

[9] H. Li, L. Shen, P. Love. Ann-based mark-up estimation system with self-explanatory capacities. Journal of Construction Engineering and Management, 1999, 125(3): 185-9.

[10] R. McCaffer, F. Harris. Modern construction management, 5th edn. Blackwell Science Ltd, 2001.

[11] O. Moselhi, T. Hegazy, P. Fazio. Neural networks as tools in construction. J. Constr. Engrg. Mgmt., 1991, 117(4): 606-625. ASCE.

[12] G. Oberlender, S. Trost. Predicting accuracy of early cost estimates based on estimate quality. 2001, J. Constr. Eng. Manage., 127(3): 173-182.

[13] A. Tavakoli, J. Utomo. Bid markup assistant: An expert system. Cost Engrg. J., 1989, 31(6): 28-33.

[14] M. Wanous, A. Boussabaine, J. Lewis. Tendering factors considered by syrian contractors. in: Proceedings of the 14th annual ARCOM conference, vol. 2, 1998, 535.

[15] J. Whittaker. managerial judgment in a competitive bidding model. Phd thesis, city university, 1970.

[16] J. Whittaker. Implementing a bidding model. Journal of the operational research Society, 1981, 32: 11-17. 